\title{
Functional Health Literacy of Asylum Seekers and Refugees - A Pilot Study in Italy
}

\author{
By Giulia Marchetti* \\ Milena Sorrentino ${ }^{\dagger}$ \\ Anna Rita Maruccit \\ Giovanni Galeoto" \\ Maurizio Marceca ${ }^{\circ}$ \\ Julita Sansoni ${ }^{\star}$
}

\begin{abstract}
Literature shows how some groups of populations, among which are people seeking international protection and refugees, find it difficult to access services in national health systems. Usually, asylum seekers have limited Health Literacy (HL), which makes understanding the appropriate health information difficult. The objective of this research is to consider the relationship between how people requesting international protection and refugees approach the Italian Health System to request health services and their level of Functional Health Literacy (FHL). These relationships are examined through mixed methods. Data were obtained using several tools: a self-administered questionnaire in which the subjects revealed social and demographic data and a face-to-face interview together with the S-FHL Scale fulfillment in order to identify the functional level of HL. Twenty-one subjects were interviewed in two Centers of Protection System for Asylum Seekers and Refugees (SPRAR). Results show a picture of the actual situation. Data report a problematic or insufficient FHL level. Some factors, such as gender, age and health perceptions, play a role in the FHL levels. Some racial prejudices were reported. Language barriers had the most impact on the communication gap. Nevertheless, none of the subjects were denied health services. In conclusion, although this study is a pilot, we have experienced difficulty in obtaining asylum seekers' trust to be open about their experience. This explains the number of the sample that should be more indicated for a qualitative study. Our results are in accordance with literature for inadequate level of FHL and lack of knowledge of the Italian Health System. This study highlighted several other issues to be taken into consideration for future research on the subject.
\end{abstract}

Keywords: Access to Health Care, Asylum Seekers, Health Literacy, Health Services, Refugees

\section{Introduction}

According to Nutbeam, Health Literacy (HL) is the ability of a subject to access, comprehend and utilize information that will allow them to promote and maintain a good state of health. These abilities are described as functional, interactive or critical, as described below:

- Functional - ability to read and write at a basic level to comprehend and utilize health information;

- Interactive - includes advanced literacy and cognitive abilities that will facilitate interaction with health personnel, which will allow an enhanced capacity to interpret and apply information given;

\footnotetext{
*Nursing Research Unit, Public Health Department, Sapienza University of Rome, Italy.

${ }^{\dagger}$ Nursing Research Unit, Public Health Department, Sapienza University of Rome, Italy.

*Nursing Research Unit, Public Health Department, Sapienza University of Rome, Italy.

'Research Fellow, Public Health Department, Sapienza University of Rome, Italy.

Associate Professor, Public Health Department, Sapienza University of Rome, Italy.

`Counselor \& Associate Professor, Nursing Research Unit Head, Public Health Department, Sapienza University of Rome, Italy \& Full Professor, Primoskem University, Slovenia.
} 
- Critical - represents more advanced cognitive abilities that will help a deeper understanding of the information thus giving patients more control on their health choices (De Caro et al. 2015).

Literature shows that the section of the population with a lower level of HL is the one that includes lower socioeconomic status, among which we find ethnic minorities, immigrants, the elderly, the disabled and people with chronic diseases (Public Health England 2015, WHO 2013).

Limited HL is conducive to scarce compliance with medical practices, due to lack of understanding, which will reflect in worse well-being, as well as medical errors. These occur mostly because people with lower HL find it difficult to interact with the health-care system and medical personnel, causing delay in access to care, difficulties in navigating the health system and low utilization of prevention services. Moreover, people with low HL do not possess a good perception of their health and strategies they can use to ensure an optimal wellbeing. They cannot manage their chronic conditions due to lack of knowledge; they overuse emergency rooms; and they are usually inpatients for longer periods (Public Health England 2015, Schnitzer et al. 2011).

On the contrary, an adequate level of HL is a valuable asset that enables patients to make appropriate decisions for their health, which will produce better health outcomes. According to the WHO, Health Literacy is a predicting factor for health stronger than annual income, education and cultural background, and it also is an essential factor in disease prevention and health promotion (WHO 2013).

Based on these premises, the Nursing Research Unit of Sapienza University of Rome promoted this pilot study about the relationship between the levels of HL and access to information and healthcare services for refugees and people seeking international protection. The goal of the pilot is to understand if there is a relationship between access to health care services and HL. This article will report results of the pilot study that took place in two welcome Centers for Refugees and people requesting political asylum (SPRAR) in the Lazio Region and Rome. Particularly, the study wanted to highlight the level of Functional Health Literacy (FHL). The research questions are as follows:

- What is the level of FHL of the population above?

- How does the level of FHL influence access to the services of the National Health System?

- How does the level of FHL influence health information requests?

The pilot study will be a valid tool to delineate the limits to improving the research on HL in all the SPRAR Centers in the Lazio Region, places where asylum seekers stay, waiting for protection recognition. The SPRAR Hosting Centers promote socialization, education and autonomy to integrate better in the society ${ }^{1}$.

${ }^{1}$ For a Transcultural Reception and Relationship, 2011. Guideline for a Transcultural Reception and Relationship, Parma. Retrieved from goo.gl/X6xmpE. 


\section{Health Literacy and Refugees}

The subject of HL is very delicate with our target population (Ingleby 2012). When these people leave their country to go to another one, there is a sense of abandonment of their own culture; migrating to a different place with a different culture and customs, which are unknown for many of them, requires knowing and asking for a cadre of information, especially regarding health issues. Unfortunately, it is difficult to establish a connection and dialogue among the parties, without considering these factors. Being unable to successfully integrate oneself in a different culture can have a huge impact on the capacity of people to be able to make informed decisions about their health (Lloyd 2014). The refugees that land in Italy are quite young and in good health overall; in fact, to survive the treacherous trips, these people must be strong and only the fittest will survive the trips ${ }^{1}$. This is called the "healthy migrant phenomenon". Many of them, however, become ill afterwards, due to the difficulty of reaching health services and, also, due to exposure to a different lifestyle (Marceca and Geraci 2009). This "sickness" does not always have an organic origin; rather, it is probably related to the trauma of the migration and the possible violence endured during the trip, as well as the uncertainty of the migration itself (Affronti and Monti 2015, Ingleby 2012, Rechel et al. 2011). The health needs of refugees are not focused on the absence of disease, but rather are geared towards acquiring language and literacy training, as well as social and working integration with the host country, while at the same time making sure their cultural roots are not lost (Marceca et al. 2012). Lack of integration represents a source of stress that will influence the quality of life (Mancuso 2011).

The refugee population seems to have a low level of HL (Public Health England 2015, Riggs et al. 2016, Schnitzer et al. 2011, WHO 2013), which can cause communication problems. They request, and therefore receive, less information about their health state, thus limiting access to both treatment and health knowledge (Wangdahl et al. 2015). Subjects with low level of HL find the comprehension of oral information about their health quite difficult. There are several strategies to improve communication; one of them is to communicate in a simple way. The health operators should abstain from using medical jargon, and instead use simple terms to convey a message tailored to the single patient; moreover, it is very important to take time to explain complex procedure. It is always best practice to limit information to avoid confusion or overwhelming feelings (Mancuso 2011, Schnitzer et al. 2011). It is also good to spend more time with each patient during the visits, pairing the oral communication with easy reading material, audio cassettes, videos, interactive platforms and the teach-back method to gauge patient understanding. The teach-back technique, in fact, consists of asking patients to repeat the information given in their own words to make sure that they comprehended it (Mancuso 2011, Barry et al. 2013). Some approaches entail both the availability of information written in a variety of languages and free mediation services to help translate. The cooperation between mediators and health operators will provide not just a linguistic mediation, but also a cultural one (Bradby et al. 2015, Devillé et al. 2011, Rechel et al. 2013).

\footnotetext{
${ }^{1}$ Report on International Protection in Italy, 2015. Retrieved from goo.gl/UQdvWd.
} 
Other effective interventions include the creation of a favorable environment where patients can be oriented. The use of instructions and signs translated in several languages will help patients not just in understanding and orienting, but also will create a sense of belonging (WHO 2013). The communication and empathetic skills of the health professionals are of paramount importance, for they can assure great results in the relationship with the subjects with low HL (WHO 2013). Moreover, the relationship between the health professionals and the refugees is a delicate one. The past traumatic experiences of the refugees may lead to mistrust towards the health personnel (Priebe et al. 2011). It may happen that they associate the health personnel and/or the doctors with a negative person of their past. The refugees have been discriminated against, and even violated, and therefore they are often afraid about reliving those situations (Affronti and Monti 2015, Ingleby 2012, Priebe et al. 2011, Rechel et al. 2011).

\section{Methodology}

\section{Sample}

The sample for the pilot study was selected from two hosting centers, one hosting males and one hosting females. Twenty-one people (18 males and three females) agreed to participate in the survey. Among them, only 16 participated in the interview, 14 males and two females. Participation in the survey was voluntary and adhered to specific criteria (Figure 1). The only exclusion criterion applied was the fact that subjects who had been in the centers for less than four weeks were not in the sample, so as to give them time to adjust to their new situation.

\section{Figure 1. Criteria of Eligibility}

- $\quad$ Age between 18 and 50 years old;

- $\quad$ One of the following: $\quad$ Be an asylum seeker;

- $\quad$ Recognized as a refugee or beneficiary of subsidiary protection;

Be a beneficiary of humanitarian protection*;

- Able to speak, read or comprehend one of the following languages: Arabic, English, Italian, Somalian, Farsi and Dari;

- $\quad$ Born outside the European Union.

${ }^{*}$ Type of Protection recognized only in Italy and regulated by Legislative decree 286/98.

\section{Materials}

The tools for the pilot study are articulated in two questionnaires and one interview.

\section{Questionnaire 1}

This part was built specially to collect socio-demographic data. Specific questions about their past or the reasons why they came to Italy were not asked to avoid reliving their traumas. 
$\underline{\text { Swedish Functional Health Literacy Scale (S-FHL Scale) }}$

The scale aimed to investigate functional HL (Wangdahl et al. 2015). The SFHL scale comprises five items, and it is in English, Somali, Arabic, Dari and Farsi. The scale explores the difficulties in reading and understanding words or numbers and comprehending health information. The results of the scale will report levels of functional literacy that are adequate, problematic and insufficient. Our pilot will be included for the ongoing Italian validation of the scale.

\section{Interview}

The questions, created especially for the discussion, investigate the refugees' knowledge of the Italian National Health Service (NHS), what it is and how to access it, as well as the knowledge of their health rights and the difficulties or fears they experience during access to care in Italy. Just like in Questionnaire 1, any reference to participants' past experiences has been avoided, unless they were willing to speak about these outside the inquiry topic.

\section{Language/cultural mediator}

For those who needed it, linguistic mediation was made available.

\section{Method}

The ethical approbation was given before the start of the investigation. The tools and the interview were subjected to the supervision of the Centers to ensure the protection of the participants. The requests to participate issued to individuals at the two Centers were conducted in two different ways: in the male center we approached guests directly; on the other hand, some difficulties were found in the female center, so guests were approached by internal operators. Questionnaire 1 was administered together with the S-FHL scale, in an individual and anonymous manner to respect the ideas and integrity of everyone. The participants were followed individually to give first the written part and then, immediately after, the interview. This mode was needed because some of the participants encountered illiteracy problems or asked questions about meaning, and so it was necessary to follow and support them without suggesting answers. The S-FHL scale was administered following established guidelines (Martensson and Wangdahl 2015). These require that researchers leave all the time needed to answer without limitation and be able to explain the questions. It is also recommended not to confine the definition of health information to something specific, but to leave it to the free interpretation of each subject. The interview was conducted with the help, if needed, of linguistic mediation. There were no time limits, and before proceeding, the rules about freedom to answer or abstain and anonymity were reiterated.

\section{Results}

Table 1 shows the results of Questionnaire 1 and the S-FHL Scale for each participant. Twenty-one subjects agreed to the questionnaire and scale compilation. Sixteen total people were interviewed, 14 men and two women. For each question, all the individual responses were analyzed and categorized into thematic 
Vol. 5, No. 2 Marchetti et al.: Functional Health Literacy of Asylum Seekers...

areas. Table 2 shows the thematic areas emerging for each response, along with the number of people who have expressed them.

Table 1. Results of Questionnaire 1 and S-FHL Scale

\begin{tabular}{|c|c|c|c|c|}
\hline \multirow[t]{2}{*}{ Participant $n=21$} & \multicolumn{2}{|c|}{ FHL inadequate $n=14$} & \multicolumn{2}{|c|}{ FHL problematic $n=7$} \\
\hline & Male $n=11$ & Female $n=3$ & Male $n=7$ & Female $n=0$ \\
\hline \multicolumn{5}{|l|}{ How do you feel? $n=20$} \\
\hline Very well $=5$ & 2 & 0 & 3 & 0 \\
\hline Pretty good $=3$ & 1 & 1 & 1 & 0 \\
\hline Good $=8$ & 6 & 0 & 2 & 0 \\
\hline Not well $=1$ & 1 & 0 & 0 & 0 \\
\hline $\mathrm{Bad}=3$ & 1 & 2 & 0 & 0 \\
\hline \multicolumn{5}{|l|}{ How old are you? $n=19$} \\
\hline $18-25=7$ & 2 & 1 & 4 & 0 \\
\hline $26-50=12$ & 8 & 2 & 2 & 0 \\
\hline \multicolumn{5}{|l|}{ Original Country $n=20$} \\
\hline Afghanistan $=4$ & 0 & 0 & 4 & 0 \\
\hline Senegal $=4$ & 2 & 0 & 2 & 0 \\
\hline Mauritania $=3$ & 2 & 1 & 0 & 0 \\
\hline Guinea $=2$ & 2 & 0 & 0 & 0 \\
\hline Mali = 2 & 2 & 0 & 0 & 0 \\
\hline Other $=5$ & 2 & 2 & 1 & 0 \\
\hline \multicolumn{5}{|l|}{ Are you married? $n=20$} \\
\hline Yes $=7$ & 5 & 1 & 1 & 0 \\
\hline No $=13$ & 5 & 2 & 6 & 0 \\
\hline \multicolumn{5}{|l|}{ How long have you been in Italy? $n=21$} \\
\hline Less than 1 year $=5$ & 2 & 1 & 2 & 0 \\
\hline Since $1-3$ years $=11$ & 7 & 2 & 2 & 0 \\
\hline Since $3-5$ years $=2$ & 1 & 0 & 1 & 0 \\
\hline Since $5-10$ years $=3$ & 1 & 0 & 2 & 0 \\
\hline \multicolumn{5}{|l|}{ Do you have children? $n=20$} \\
\hline Yes $=9$ & 5 & 3 & 1 & 0 \\
\hline $\mathrm{No}=11$ & 5 & 0 & 6 & 0 \\
\hline \multicolumn{5}{|l|}{ How did you get to Italy? $n=20$} \\
\hline Boat $=8$ & 4 & 1 & 3 & 0 \\
\hline Plan $=8$ & 5 & 1 & 2 & 0 \\
\hline Truck $=2$ & 1 & 0 & 1 & 0 \\
\hline Bus $=1$ & 1 & 0 & 0 & 0 \\
\hline On foot $=1$ & 0 & 0 & 1 & 0 \\
\hline \multicolumn{5}{|l|}{ With who did you arrive in Italy? $n=21$} \\
\hline Alone $=16$ & 10 & 2 & 4 & 0 \\
\hline Friends $=4$ & 1 & 1 & 2 & 0 \\
\hline Family $=1$ & 0 & 0 & 1 & 0 \\
\hline \multicolumn{5}{|l|}{ How do you think is your health? $n=21$} \\
\hline I have no health problems $=10$ & 5 & 0 & 5 & 0 \\
\hline I almost never have health problems $=1$ & 1 & 0 & 0 & 0 \\
\hline I often have health problems $=5$ & 3 & 0 & 2 & 0 \\
\hline I have one or many health problem $/ \mathrm{s}=5$ & 2 & 3 & 0 & 0 \\
\hline \multicolumn{5}{|c|}{ How many years did you go to school in your country? $n=21$} \\
\hline Less than 3 years $=6$ & 4 & 2 & 0 & 0 \\
\hline $5-10$ years $=8$ & 3 & 1 & 4 & 0 \\
\hline $10-15$ years $=4$ & 2 & 0 & 2 & 0 \\
\hline $15-20$ years $=3$ & 2 & 0 & 1 & 0 \\
\hline \multicolumn{5}{|l|}{ What is your faith? $n=21$} \\
\hline Muslim = 17 & 9 & 2 & 6 & 0 \\
\hline Catholic = 1 & 1 & 0 & 0 & 0 \\
\hline Orthodox $=1$ & 0 & 1 & 0 & 0 \\
\hline Atheist $=1$ & 0 & 0 & 1 & 0 \\
\hline Other $=1$ & 1 & 0 & 0 & 0 \\
\hline
\end{tabular}


Table 2. Thematic Areas of the Answers Emerged from the Interview with the Number of Participants who Gave Them

\begin{tabular}{|l|l|l|}
\hline 1. Have you ever had health problems? If so, & 2. Is there a health system in your country of origin? & 3. What would you like to receive from a health service?
\end{tabular}

can you tell me what?

- 3 men have no health problems

- 13 participants yes

- 14 participants come from countries where access to health

services need to be paid for

- 2 could not answer

- 5 possibilities of access to care for all with staff trained and

not discriminating against people

- 5 no answer

- 3 best organization of services

- 1 more consideration

- 1 more emphasis on nurses

- 1 mental health services

\section{Explain to me, in your words, what is} public health system in your opinion?

- 10 could not answer

\section{Did you enjoy the services of the Public Health System?}

- 14 yes (long wait times and wrong knowledge)

- 2 no

cannot pay, exemptions

3 stated: free access to basic or specialist

medical care (mental health)

\section{Do you feel like you don't understand or} you are not understood?

- 5 no, because there are mediators, friends

operators who speak multiple languages

- 2 before there was a language barrier, not now

- 3 yes

1 no, but there are problems because doctor

do not explain the results or procedure

\section{Do you know how to apply for a}

3. Do you know how to
healthcare benefit?

- 8 yes

- 7 no

$\bullet 7$

your health conditions?
7. Do you know someone who could help you in case of health problems (a doctor, a nurse)? How did you meet health

- 16 yes. Of which 1 met through Local Health Authority through the center that houses them now

11. As soon as you arrived in Italy, was it explained to you As soon as you arrived in Italy, was it explained to you
what were your health rights and how to access them? If so, by whom?

6 yes. Through LHAS or reception Center

- 4 informed by friends

- 6 no

15. In your words what, in your opinion, might be useful to you or others under the same conditions to improve knowledge and access to the Health Service? - 5 I do not know

- 6 explain, raise awareness and train through courses

- 2 break the language barrier

- 1 to increase the confidence of the operators

- 1 night, everyone should inquire on their own

- 1 facilitate access Service (LHAS), 1 through friends, 1 unspecified and 13

\section{Have you ever been afraid to go to the doctor? Can you} tell me why?

- 11 no

- 2 lack of explanation of the procedures or examinations

- 1 lack of confidence

- 1 problem with relationship with the operators

- 1 fear for too much waiting time

14. In your words, what in your opinion, might be useful to you or others under the same conditions to improve

- 4 improve communication, listening and mediation

- 4 healthy lifestyles

- 3 best organization (appointments, competent and available staff)

- 2 nothing

- 2 consideration of opinions or stress

- I do not know
4. Since you came to Italy, has anyone explained to

you what the public health system is?

- 12 no

- 4 yes

8. Explain to me, in your words, what difficulties did you find in accessing the services? What do the difficulties depend on according to you?

- 5 no difficulty

- 5 language barrier and communication difficultie

- 3 waiting times

- 2 racism and distrust of the operators

- 1 understand how exemptions and documents work

\section{It is important to know how to take advantage} of the Public Health System?

- 16 yes

\section{Do you go regularly to a place of worship?}

8 , in the mosque

- 1 no. Atheist

- 2 in the center or in the room

- 4 not a specific one, everywhere (1 in the mosque)

Source: Own elaboration. 


\section{Discussion}

Due to the scarce results (pilot), it is not possible to see a statistical correlation between the results of Questionnaire 1 and those of the S-FHL scale. However, from what emerged from the results of the S-FHL scale, none of the 21 participants possesses a sufficient level of FHL. Fourteen participants out of 21 have an inadequate level, and seven out of 21 have a problematic level (Table 1). The inadequate percentage of FHL is $66.7 \%$ versus the problematic one, which is $33.3 \%$ (Table 3).

Table 3. Representation of Data Processed by The S-FHL Scale

\begin{tabular}{|l|l|c|c|c|c|}
\hline \multicolumn{6}{|c|}{ FHL } \\
\hline & & Frequency & \% & Valid \% & Cumulative \% \\
\hline \multirow{3}{*}{ Valid } & Inadequate & 14 & 66.7 & 66.7 & 67.7 \\
\cline { 2 - 6 } & Problematic & 7 & 33.3 & 33.3 & 100.0 \\
\cline { 2 - 6 } & Total & 21 & 100 & 100.0 & \\
\hline
\end{tabular}

Source: Own elaboration.

Participants can be divided into two groups based on age. The first includes seven participants between the ages of 18 and 25, three who have an insufficient FHL and four with a problematic one. The second group ranges from 26 to 50 years of age and includes 12 people, 11 of whom have insufficient FHL.

Investigating the relationship between schooling and FHL reveals conflicting data. All those participants who claimed to have undergone less than three years of schooling reported an inadequate FHL level $(n=6)$. The same inadequate level of FHL is reported by who studied from 5 to 10 years, from 10 to 15 years and also by two of the three subjects reporting 15 to 20 year. Regardless of the years of schooling, the results show a higher percentage of the inadequate level.

The countries with the highest provenance are Afghanistan and Senegal. From the first, there are four subjects, three with a problematic FHL level and one with inadequate. From Senegal, there are also four people, two with inadequate FHL and two problematic. From Mauritania, Guinea and Mali are respectively three, two and two subjects, all with an inadequate FHL.

Travel types do not seem to have a strong relationship with FHL level, but they do show some interesting results. The arrival methods in Italy most used by the population surveyed were aircraft and boat; both solutions were chosen by eight people. There is a greater number of insufficient FHLs $(n=6)$ in the number of people arriving by plane than those arriving by boat $(n=5)$. Other solutions used by the people included in the study were through trucks, coaches and even on foot. This evidence breaks down the assumption by many people that the only way an asylum seeker arrives in our country is by sea. It is mistakenly blamed for the media campaigns that pass this message (Affronti and Monti 2015).

The amount of data gathered is insufficient to define a clear relationship between the time spent in Italy and S-FHL scale. However, the data show that there is an increase in the amount of insufficient FHL during the first three years of stay in Italy. After 3-5 years, the situation between insufficient and problematic FHL is equal. Instead, the number of people with a problematic 
FHL seems to increase after 5-10 years of stay in our country. It can be noted that the percentage of insufficient FHL is greater in people who are in Italy for a maximum of three years (nine out of 21). Instead, the problematic FHL remains constant over time.

Most of the participants in the study were within the 1-3-year period. This is because many of the people who come to our country do not want to stay in Italy, and as soon as they get the documents they move to other European countries. In fact, according to the current laws of the Dublin Agreement, an asylum seeker must begin the procedures for the recognition of status and obtain the documents in the first European country to which he comes ${ }^{3}$.

The question "How do you feel about your health?" wants to investigate the perception of health and whether there is a relationship with the FHL level, as depicted in the literature (Wangdahl et al. 2014, WHO 2013). Facing the level of the S-FHL scale, there seems to be a relationship between the perceived state of health and the level of FHL. Those who complain of more serious problems have an inadequate level. There was a notable difference between men and women, as well. All women claimed to have one or more severe health problems in the questionnaire. On the other hand, ten of the men said they did not have any health problems, contrary to what they said in the interview.

During the interviews, out of 16 respondents, only three men reported no health problems. This figure disagrees with those emerging from the first question of Questionnaire 1 "How do you feel?" where almost everyone reported to be fine. They all were more sincere during the interview than during the questionnaire.

A significant fact that may be related to the levels of FHL found is that all participants come from countries where health is not accessible to all:

It is not that it exists, but if you are sick and pay they will take care of you. If you have the money and a big problem is better you go to India to receive care, it is the doctor who advises you to do that. There aren't free hospitals for Afghan population.

One of the women reported an episode that required care and assistance, but she did not seek or receive such medical help:

I do not know, I've never been to the hospital. I gave birth four times at home.

Probably this also indicates a lack of health culture. Not having free access to services is a very serious problem. When asked what they would like to receive from a healthcare system, five responded that they would want access to care for everyone with trained and professional staff who do not discriminate against people:

Since health is important and crucial I would like it to be more available with less discrimination. I would like the staff to be more professional and not to tease the patients (if I am on the ambulance because I'm sick why do they tease me?). Foreigners need to be helped just like the Italians.

\footnotetext{
${ }^{3}$ Report on International Protection in Italy, 2015. Retrieved from goo.gl/UQdvWd.
} 
One of the subjects reported in an interview that in Africa mental health is not considered and, as a result, people who suffer from it are not helped. In Italy, he found a different situation. As WHO states, health is a "state of complete physical, mental and social well-being, and not the mere absence of the state of illness or infirmity" (Davies et al. 2006).

In Africa, I never had a doctor to talk about psychic problems, here in Italy I do, and it is important. Psychology in my Country is not recognized, you do not know how to cure it. Lately it is being discussed, but not like here. I found out this when I was doing interpreting to other guys in another center.

However, the knowledge of what a public health system can offer is very vague, and 12 respondents report that nobody explained what it is or does. Many report that they have learned it by themselves or through friends. From these responses, it shows that friends are used as guides in services or as translators. As a result, they do not know exactly what it is:

Citizens do not pay, the state does.

The system is based on exemptions people have a health card.

There is a primary doctor and specialist visits.

Thirteen of 16 subjects have benefited from six services since being in Italy. Yet, in answering this question, they reported some critical issues, for example:

Once I had a problem in my eyes and the doctor had put me in the list for the next 10 days. Instead, in 2007 a friend of mine had a problem with the teeth, and we used to go to the emergency room every day because we did not know how to receive care for them. My friend was very sick and in a lot of pain, but they gave him the appointment after 4 months.

According to the study of Priebe et al. (2011), organizational problems and the poor knowledge of where to go when a problem arises are very common, as in this case. Often migrants find it difficult to understand their rights, and confusion is increased by the fact that different rights and access possibilities exist in European countries (Bradby et al. 2015).

It should be recalled that in Italy, pursuant to Art. 34 of Legislative Decree $286 / 98^{4}$, asylum seekers, refugees and beneficiaries of protection have the right to enroll in the NHL and access services just as Italian citizens. The Italian

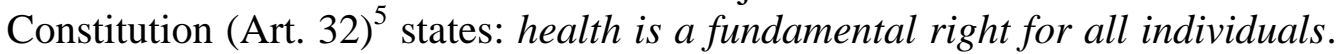
Therefore, everyone has the right to free access to the Italian NHS and be treated. At times, based on treatments, a minimum economic participation, called ticket, is required. On the other hand, many exemptions exist for those who

\footnotetext{
${ }^{4}$ Legislative Decree (Italy). Testo Unico sull'Immigrazione 286/98 e succ. mod. Retrieved from goo.gl/6cKSZm.

${ }^{5}$ Italian Constitution (1946). Costituzione della Repubblica Italiana. Retrieved from goo.gl/daCMbk.
} 
cannot pay, for the indigent, for those who have serious or chronic illnesses and also for pregnant women ${ }^{6}$.

Some have made references to medical examinations that have been scheduled for awhile. This is a good sign, along with the fact that everyone refers to having a basic physician. Thirteen subjects informed us that they met their primary doctor through the centers where they are now guests.

As for the difficulties of access, among those who answered none, a woman said that her main problems come from other sources, and they are linked to the abandonment of homes and family.

Five reports claimed that communication with operators (to make appointments or book specialty visits) is one of the greatest difficulties encountered. In this category, we also include those who claim to have no problems because they are accompanied by a friend who speaks Italian. Communication can be a crippling barrier; although, some of the refugees try to break it down by using Italian-speaking friends or host center workers. These remedies are not always optimal, however. Friends or family members may choose to be selective in what they translate, summing up or even censoring part of the message (Priebe et al. 2011). Instead, it is necessary to increase the number of mediators within the structures.

Major organizational problems have been described by three guests as including a long waiting time. Priebe et al. (2011) also states in his work that one of the most perceived problems is organizational. Two young men report problems related to cultural differences and racial prejudice from the staff and other patients. People who come from African countries, and therefore who have dark skin, indicated many more racial problems than the rest of the population under investigation. We know that the prejudice of the operators unfortunately affects negatively the quality of the services provided (Sienkiewicz n.d.).

I spent a lot of time without going to the doctor because I was fighting with the operators during blood tests. And so, it took a long time before I went back to the doctor. Nobody explained what I had to do, and they did not respect me when they were drawing blood. They took too much blood. I believe that the doctor and nurse are a noble profession because even if you cannot pay your health has no price, but in the hospital, people are treated as ignorant foreigners. We are all foreigners to someone on earth, so we all should respect each other. Once to have a check on my eyesight I waited 4 hours, for everybody was ahead of me even though I was ahead of them. I can wait and have no problem doing it if there is any reason, but it is not fair that people pass me on. I have anxiety to go to the hospital or to the police station because I must wait longer than the Italians. There is a racial problem. But we all have red blood.

Cultural differences create barriers, and if operators are unable to cope with or do not have adequate training, there may be a shift away from services, so that the refugees will not participate in the health care services (Davies et al. 2006, Priebe et al. 2011).

\footnotetext{
${ }^{6}$ Minister of Health (n.d.). Retrieved from goo.gl/n6isHW.
} 
Although some of the subjects interviewed state that they have no problems in getting information or being understood, because they are being accompanied by friends, this shows that there are barriers (Davies et al. 2006, Rechel et al. 2013, Scheppers et al. 2006).

As already reported, many of the participants use friends as sources of information by bringing them to visits or using them as translators. This, on one hand, highlights the importance that the ethnic community can have, but on the other it shows a failure of our services. It is unacceptable that healthcare or management personnel in a hospital have no language or cultural skills to accommodate foreigners; the lack of mediators in our healthcare facilities is not a symptom of quality. The information translated by friends is not always expressed correctly or faithfully (Priebe et al. 2011). This kind of mediation, especially for health information, is based on people who speak our language, but it does not mean that they have an adequate HL along with their skills to understand what they are translating. Unfortunately, the presence of mediators in public hospitals is not guaranteed.

The guest, whose testimony has been reported above, said he was not afraid but still felt bad about how he had been treated. Another guest says:

I'm afraid to go to the doctor because I do not know them and the procedures they prescribe. I noticed that the health operators did not explain the procedures I must do. I was scared when I did not have the documents. But a friend of mine told me that I could go to the hospital even without. I must do a medical procedure and nobody told me what it is and what doctors do. Some of the operators here (in the Center) explained it a little.

Healthcare providers do not realize how their prejudices or their knowledge greatly affect access to services.

Two Senegalese young men say that they do not trust the blood drawing procedure, as in the above interview, because they are not used to testing blood. These are examples of cultural barriers (Davies et al. 2006, Priebe et al. 2011). Staff should be very prepared on cultural issues related to diseases or treatments (Devillé et al. 2011). Trust is also another barrier:

I did not go to some of the appointments because I could not trust them. They came in two to make a visit. And I had to undress, I have no problem doing it, but I just could not trust them.

As reported in the literature, establishing a trusting relationship with healthcare professionals is not always easy, because trust is difficult to create (Affronti and Monti 2015, Ingleby 2012, Priebe et al. 2011, Rechel et al. 2011). Even during the study, a major problem emerged in creating a trusting relationship, especially with female guests. However, one woman shows satisfaction with the possibility of being treated and receiving assistance:

Not at all, because in Italy they are very kind and they all help. 
Sixteen subjects report that they had been informed about their health rights and how to use them from LHAS, the Centers they have been or from friends; others deny being informed about their rights. Unfortunately, these answers confirm that lack of knowledge of their rights prevents access to care (Priebe et al. 2011, Rechel et al. 2013). In addition, information coming from friends is not always true and can even be absolutely wrong:

No. when I was in another Center I used to cry all the time, I stayed in bed and cried all the time. I cried because my scars were sore and I left my kids back home. Somebody told me that I could not go to the doctor without documents and I was very worried [...].

In the answer the information received from a friend about not being able to access health services without papers is incorrect. This is because in Italy it is possible for regular migrants to join NHS (Legislative Decree 286/98). Even non-regular people, without papers, can access services via the temporary present foreigner (STP) code. It is a special code issued without a passport or other documents; it has a six-month validity and is used to identify the foreign person for the repayment of healthcare benefits in both public and private facilities (Luzi et al. 2013).

However, the hosting centers in which the survey was conducted seem to be very aware of the problem, and they offer a point of reference in providing both the information and in guaranteeing access to services, as seen in the previous reply, in which everybody has a primary care physician. Thirteen subjects found their doctors through the centers:

Before I got here I was told by some friends, and I still had some fear/concern, but then when I came to the Center they explained everything to me.

Contrary to what is stated in the literature (Schnitzer et al. 2011), despite the insufficient level of FHL, all participants acknowledge the importance of accessing the services adequately and increasing their knowledge and use. They would like the procedures to be better explained even with special training and education courses:

Yes, especially for us foreigners, it would be better that they explained as soon as we arrived.

Eight respondents said they knew how to claim healthcare; others responded that they did not know how to do it. However, it was found that they were helped when they needed access to care and doctor's appointments.

When asked, "Explain to me, in your words, what you think might be useful to you or others under the same conditions to improve health conditions", one of the most important questions, five participants indicated the need to increase the numbers of mediators in hospitals, for dialects as well as for mainstream languages, along with an increase in the teaching of Italian. 
Finding someone who also talks dialects, not just the main languages.

This is an important question. Improving the teaching of the Italian language helps us to express ourselves better about health needs.

Three people replied that the need for health is different from person to person, and it depends on the habits of individuals. The two women interviewed report being very satisfied with the care they receive:

Only in Italy I can have the best care. Before I arrived in Italy I was in another European country in the Mediterranean, and there the care was not the best. In my life, I've lived a lot of racism and not being free. Here in Italy it is different, I have not heard racism and I'm free. If I want to go to the market, there is no problem.

As for the management of the organization, three guests suggest that hospitals should be quieter and more prepared to handle their rage against foreigners, who may not understand or do not know how the system works. They also report that appointments should be faster.

Two people reported the need to be given more consideration for their opinions:

The fact is that we all have problems and are very stressed, we should take this stress into account, and stress also hurt men and their virility.

As reported in the literature, the issues to be improved remain those of communication, organization, and human relationship between operators and patients (Bradby et al. 2015, Priebe et al. 2011, Rachel et al. 2013).

To the next question: "Explain to me, in your words, what you think might be useful for you or others under the same conditions to improve knowledge and access to the Health Service," there were not many changes from the results that emerged in the previous one. It has emerged that many participants feel the need to improve their knowledge or communication through language and information training courses.

Understanding the importance of the service, having more trust in healthcare professionals, doctors should explain more.

Put more multi-languages people in health centers.

Take down the language barrier. Organize conversations to explain how to access services.

Provide more training, perhaps with courses also in Italian schools.

\section{Limits}

The way of gathering participants was different at the two Centers. It is important to note that only 3 out of 30 females participated in the survey. In the male center, it was possible to ask directly the guests, while in the female one there was mediation by the operators. This last strategy was fallacious. Probably 
the operators did not fully understand the purpose and importance of the research. At the time of the study, a guest withdrew their availability because he did not want to do any medical examinations. The best strategy seems to be asking for adherence to the guests following a briefing on the study. If this is not possible, it is necessary to provide adequate information to the operators of the Centers. In this way, we will avoid trauma and protect the vulnerability of the guests, as well as encourage operators to promote participation by properly explaining the objectives of the study.

Mistrust is another limit. We need to talk about this because it was an obstacle in the female center. However, getting 18 male subjects to participate is a very significant achievement. It looks like a very small sample, but it is extremely difficult to break the mistrust and have the consent to participate in such studies. It has been a success for us in terms of integration and human relationships. For this, further training will be organized for those who will lead future iterations of the study. They will need to explain carefully the objectives and the ways in which the study will take place, making the participants happy, be careful to conduct the interview without making it mislead, capturing all the signs of psychological suffering. During the interview in the women's center, however, emotions ran high while the women spontaneously talked about the fact that they left their children back home, even though this information had not been requested as part of the inquiry. It was difficult to follow the pattern of the pre-set interview, either because they did not know what to answer or because they tended to tell what they felt or felt at the time.

Because it is a nursing study, it cannot be based solely on compiling questionnaires or interviews, but it should investigate the person's life in its entirety. The problem is that the people involved in the search are vulnerable and, rightly so, the center representatives have expressed their opinions on protecting them by changing or modifying some questions. It is also important for us to protect first and foremost the participants. However, it is considered necessary to find ways to investigate in the future how well the experiences have a role in the HL level and how they influence access to health information. Quality of life and experiences affect health, even if there is no disease (Mancuso 2011). To prevent the project being blocked at the request of the Centers, it is important to find an optimal way to do so.

Questions in Questionnaire 1, especially the first question "How do you feel?," were somewhat imperfect. Probably a question of the kind at the beginning could be perceived as a colloquial question and courtesy. Also, this question does not work in this position because the participants are still not comfortable with responding freely. Also, perhaps other tools could be used to investigate all the values of the HLA.

\section{Conclusion}

The data from this study are preliminary. The pilot study was mainly used to set the line to be followed for future investigation into other regional SPRAR 
realities. In conclusion, the survey showed that the target population's FHL levels are insufficient for $66.7 \%$ and problematic for $33.3 \%$ (Table 3 ).

Participants consider it essential to know how to access and use services correctly. Some participants have proposed to increase training and information to improve knowledge and access to NHS. Although knowledge is fragmented, none of the participants seem to be excluded from basic or specialist health care. Fourteen out of 16 guests report that they have found a primary care physician, enrolled in the NHS, and received information and assistance on how to access services through the center and the operators.

Health Literacy is a measurable parameter that has several levels and puts in practice all shared strategies to ensure that health information is acquired and understood. For the population concerned, it is not enough to implement programs to increase it, rather other aspects of forced migration, such as vulnerability or traumatic experiences, need to be considered. Healthcare professionals need to be adequately prepared on how to work with immigrants and how to increase the HL while helping them to improve their communication capacity. Nurses could make a huge contribution to assisting this population. The problems of asylum seekers and refugees are not only of an organic origin, for they do not necessarily have a disease. Often, their problems arise from an unsatisfied need stemming from their lives. For this reason, nurses, based on the meta-paradigm, are also professional figures who could give much in this context. In transcultural care, they practice education, awareness, support, counseling and prevention. An operator working in these areas should have, in addition to clinical, welfare and cultural knowledge, empathy and active listening skills, qualities which nurses typically have.

\section{Acknowledgments}

Special thanks to "Association Centro Astalli - Jesuit services for Refugees" of Rome for having allowed the research and for its time.

\section{References}

Affronti M, Monti MC (2015) What's focus about forced migrants? The experience of the Policlinico of Palermo. Bologna: Pendragon Editions.

Barry MM, D'Eath M, Sixsmith J (2013) Interventions for improving population health literacy: Insights from a rapid review of the evidence. Journal of Health Communication: International Perspectives 18(12): 1507-1522.

Bradby H, Humphris R, Newall D, Phillimore J (2015) Public health aspects of migrant health: A review of the evidence on health status for refugees and asylum seekers in the European Region (Health Evidence Network synthesis report 44). Copenhagen: WHO Regional Office for Europe.

Davies AA, Basten A, Frattini C (2006) Migration: A social determinant of the health of migrants. IOM Migration Health Department Geneva, Switzerland.

Devillé W, Greacen T, Bogic M, Dauvrin M, Dias S, Gaddini A, et al. (2011) Health care for immigrants in Europe: Is there still consensus among country experts about principles of good practice? A Delphi study. BMC Public Health 11(699). 
De Caro W, Caranzetti MV, Capriati I, Alicastro MG, Angelini S, Dionisi S, et al. (2015) The concept of Health Literacy and its importance for nursing. Professioni Infermieristiche 68(3): 133-142.

Ingleby D (2012) Acquiring health literacy as a moral task. International Journal of Migration, Health and Social Care 8(1): 22-31.

Lloyd A (2014) Building information resilience: How do resettling refugees connect with health information in regional landscapes - Implications for health literacy. Australian Academic \& Research Libraries 45(1): 48-66.

Luzi AM, Pasqualino GM, Pugliese L, Schwarz M, Suligoi B (2013) Access to care for the foreign persons: Operating instructions. Roma: Istituto Superiore di Sanità.

Mancuso L (2011) Overcoming health literacy barriers: A model for action. Journal of Cultural Diversity 18(2): 60-67.

Marceca M, Geraci S (2009) Refugees, asylum seekers and the right to health. In Italian Global Health Watch. Global Health and Development Assistance. Rights, Ideologies and Deceit. Pisa: Edizioni ETS.

Marceca M, Geraci S, Baglio G (2012) Immigrants' health protection: political, institutional and social perspectives at international and Italian level. Italian Journal of Public Health 9(3).

Martensson L, Wangdahl J (2015) Scale for functional health literacy Swedish version Guidelines for use of the scale. University of Gothenburg and University of Uppsala.

Priebe S, Sandhu S, Dias S, Gaddini A, Greacen T, Ioannidis E, et al. (2011) Good practice in health care for migrants: Views and experiences of care professionals in 16 European countries. BMC Public Health 11(187).

Public Health England (2015). Local action on health inequalities - Improving Health Literacy to reduce health inequalities. London: PHE.

Rechel B, Mladovsky P, Devillé W, Rijks B, Petrova-Benedict R, Mckee M (2011) Migration and health in the European Union: An Introduction. Maidenhead: Open University Press.

Rechel B, Mladovsky P, Ingleby D, Mackenbach JP, McKee M (2013) Migration and health in an increasingly diverse Europe. Lancet 381: 1235-1245.

Riggs E, Yelland J, Duell-Piening P, Brown SJ (2016) Improving health literacy in refugee populations. The Medical Journal of Australia 204: 9-10.

Scheppers E, van Dongen E, Dekker J, Geertzen J, Dekker J (2006) Potential barriers to the use of health services among ethnic minorities: A review. Family Practice 23: 325-348.

Schnitzer AE, Rosenzweig M, Harris B (2011) Health literacy: A survey of the issues and solutions. Journal of Consumer Health on the Internet 15(2): 164-179.

Sienkiewicz D (n.d.). Access to health services in Europe. European Social Watch Report $17-20$.

Wangdahl J, Lytsy P, Martensson L, Westerling R (2014) Health literacy among refugees in Sweden - A cross-sectional study. BMC Public Health 14(1030).

Wangdahl J, Lytsy P, Martensson L, Westerling R (2015) Health literacy and refugees' experiences of the health examination for asylum seekers - A Swedish cross-sectional study. BMC Public Health 15(1162).

Wangdahl J, Martensson LI (2015) Measuring health literacy - The Swedish functional health literacy scale. Scandinavian Journal of Caring Science 29: 165-172.

WHO (2013) Health literacy. The solid facts. Copenhagen: WHO Regional Office for Europe. 
